\title{
The Investigation and Analysis of Pre-Service Teachers TOWARD TPACK Competencies
}

\author{
Yuxi Wang, Xiaomei Gu*, Sifan Liu \\ School of Foreign Languages and Cultures, Nanjing Normal University, Nanjing, China \\ Email: *371323427@qq.com
}

How to cite this paper: Wang, Y. X., Gu, X. M., \& Liu, S. F. (2020). The Investigation and Analysis of Pre-Service Teachers TOWARD TPACK Competencies. Open Journal of Social Sciences, 8, 327-339. https://doi.org/10.4236/jss.2020.812027

Received: December 10, 2020

Accepted: December 25, 2020

Published: December 28, 2020

Copyright $\odot 2020$ by author(s) and Scientific Research Publishing Inc. This work is licensed under the Creative Commons Attribution International License (CC BY 4.0).

http://creativecommons.org/licenses/by/4.0/

\begin{abstract}
Better playing the role of TPACK in the teachers' professional knowledge system calls for the exploration of the relationships between every two levels of TPACK of pre-service teachers. The research data were collected from 232 pre-service teachers studying at Nanjing Normal University. Through the collection and analysis of relevant literature, the purpose of this study was to reveal the current situation of pre-service teacher TPACK and its existing problems, and put forward corresponding countermeasures and suggestions. The results showed that in the TPACK scale, comparatively high scores were measured on the PCK and PK subscales while pre-service teachers attained relatively low scores on TPCK subscale; a positive correlation was discovered between every two levels of pre-service teachers' TPACK; gender level differences showed up at CK level, while no gender level differences existed at the other levels; in terms of the variable of year level diversities were observed at TPCK and PCK level, while no year level diversities occurred at other levels.
\end{abstract}

\section{Keywords}

Pre-Service Teachers, TPACK, Information Literacy

\section{Introduction}

As the information technology has become a going concern, an acceleration in educational informationization reformation occurs where teachers dominate the informationization construction. The knowledge teachers' possess has become indispensable in the development of education informationization. Technological Pedagogical Content Knowledge was presented at the earliest times (Mishra \& Koehler, 2006). Nowadays, the development of the information requires modern teachers acquiring sufficient information literacy to reconstruct the original knowledge structure and to form a new knowledge system fitting the 
need for combining information literacy and disciplinary knowledge. Teacher education bears the responsibility of cultivating teachers of the new generation attributed to the TPACK framework being an innovative direction of teachers' development with regard to informationization, thus having become a tendency for research in teacher education and the advancement of the teachers' knowledge structure. At present, most of the curricula of pre-service teachers in China mainly focus on either theoretical guidance or technological ability training, ignoring training pre-service teachers' ability to integrate information technology with teaching into practice. As a result, pre-service teachers fail to make meaningful alterations to the teaching process when applying information integrated teaching to simulated teaching (Cuban, Kirkpatrick, \& Peck, 2001). In the investigation into the integration of information technology and subject teaching of pre-service teachers with their internships finished, it was revealed that pre-service teachers' integration of information technology with classroom teaching is not sufficiently effective. Given this finding, this study took 232 pre-service teachers from Nanjing Normal University to investigate the current status of different levels of pre-service teachers' TPACK and to analyze the features of pre-service teachers' TPACK at all levels expected to provide guidance on the future pre-service teachers training.

\section{Literature Review}

With the fast growth of information technology, ICT will also influence the teachers' knowledge structure. Punya Mishra and Matthew Koehler (2006) put forward the concept of TPACK-short for Technological Pedagogical Content Knowledge, and they explain how to integrate information technology into teaching practice evolving from Shulman's (1986) PCK (Pedagogical Content Knowledge) framework-the conversion of the teacher-centered class into an active and cooperative class where teachers focus more on the integration of technology, pedagogical knowledge and content knowledge in the informationization environment.

The three core knowledge levels of TPACK: content knowledge (CK), technology knowledge (TK) and pedagogical knowledge (PK) and four compound knowledge levels formed by the three core knowledge levels: PCK, TPK, TCK, TPCK are highly integrated and complex knowledge about how teachers utilize technology in practical teaching. The nexus among all these elements is illustrated in Figure 1.

Since the TPCK knowledge framework was officially advanced, extensive attention has been received in the field of teacher education development and educational technology (Mishra Koehler, 2009). Accompanying the advancement of information technology, scholars continue further studies on TPCK. One strand is that scholars placed the development of teachers' TPCK in a complex context and the other strand was that the mutual influences between the various elements within TPCK were split up. Now more and more researchers 


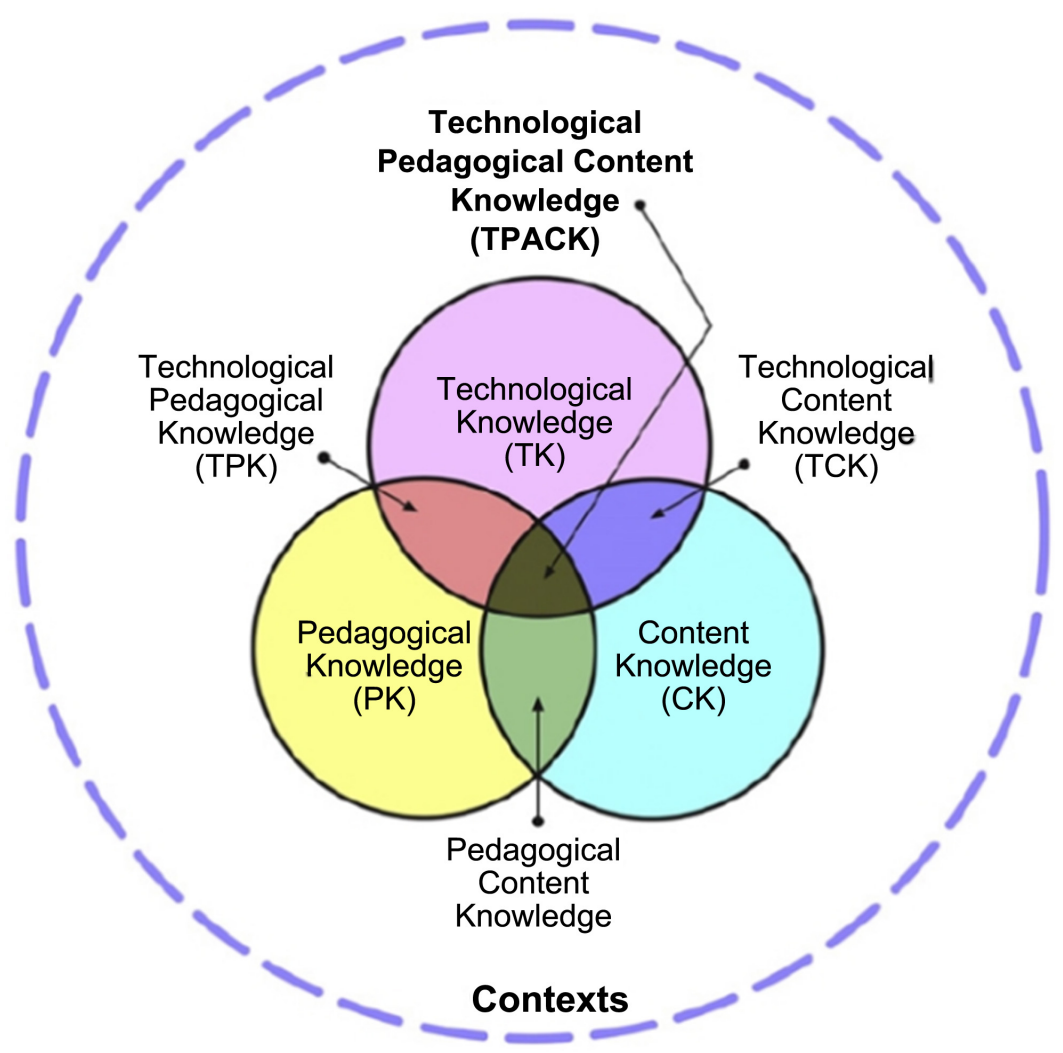

Figure 1. Graphic representation of technological pedagogical content knowledge (TPACK).

are concerned about how the technology in TPCK is integrated with teaching. In recent years, there have been many studies on the measurement and development of PTs' TPACK abroad (Zhan \& Ren, 2010). Angeli \& Valanides (2009) believe that a vital research direction is about how to effectively apply information technology to teaching, while domestic research concentrates more on the integration of information technology and class (Yuan, 2014). Xu (2012) reports that the TPACK framework provides new ideas for the integration of information technology and disciplinary curriculum in terms of theoretical improvement, teacher education, teaching practice and many other aspects, which will help promote the development of PCK and provide a strong basis of PK for the informationization education. The research on the pre-service teachers' knowledge of classroom teaching informationization gradually increases (Zhang \& Wang, 2016), especially focusing on the impact of different knowledge levels on pre-service teachers' TPACK knowledge at different levels and under different backgrounds (Dai, Ren, \& Li, 2018). Teachers of the new generation in the 21st century should not only pay attention to the improvement of TK, PK and CK, but to how to integrate different levels of knowledge for the purpose of cultivating teachers and developing teacher education as well.

In summary, TPACK provides a good framework for the knowledge system of pre-service teachers' training. Specifically, the effectiveness and applicability of the TPACK in the present study need to be further explored. In view of this, this 
study has raised the following research questions as follows: What are the meanings of PTs on all levels of TPACK? What is the correlation among every level of PTs' TPACK and personal background factors? What are the cures and suggestions for the TPACK improvement of pre-service teachers' education in China?

\section{Research Methods}

\subsection{Research Object}

The participants of this study were 232 pre-service teachers of five majors selected from Nanjing Normal University for investigation, including majors of pre-service English, pre-service History, pre-service Physics, pre-service Chemistry, and pre-service Mathematics. A total of 232 questionnaires were sent online powered by www.wjx.cn. After excluding invalid ones, the final quantity of useable ones was 223 with the effective usage rate of questionnaire being $96.1 \%$. The ratio of male participants to female participants was close to 1:1, and to be more specific the number of participating females (126, accounting for approximately $56.5 \%$ ) was slightly higher than that of participating males (97, accounting for approximately $43.5 \%$ ). Of those participants of this survey, $25.4 \%$ was freshmen, $25.6 \%$ was sophomores, $26.9 \%$ was juniors, and $22.1 \%$ was seniors (see Figure 2).

\subsection{Research Instruments}

The present study adopted the TPACK questionnaire developed by Archambault and Crippen (2009), which has been appropriately adapted and designed in this study to form an innovative one meeting local peculiarities and needs. Online enquiries were conducted for data collection, and meanwhile communications and contact were also established with relevant teachers and pre-service teachers for the purpose of conducting random enquiries for the pre-service teachers among them. During these processes, the participants were asked to scan the QR code or a link would be sent to them to fill in the questionnaire. The subject

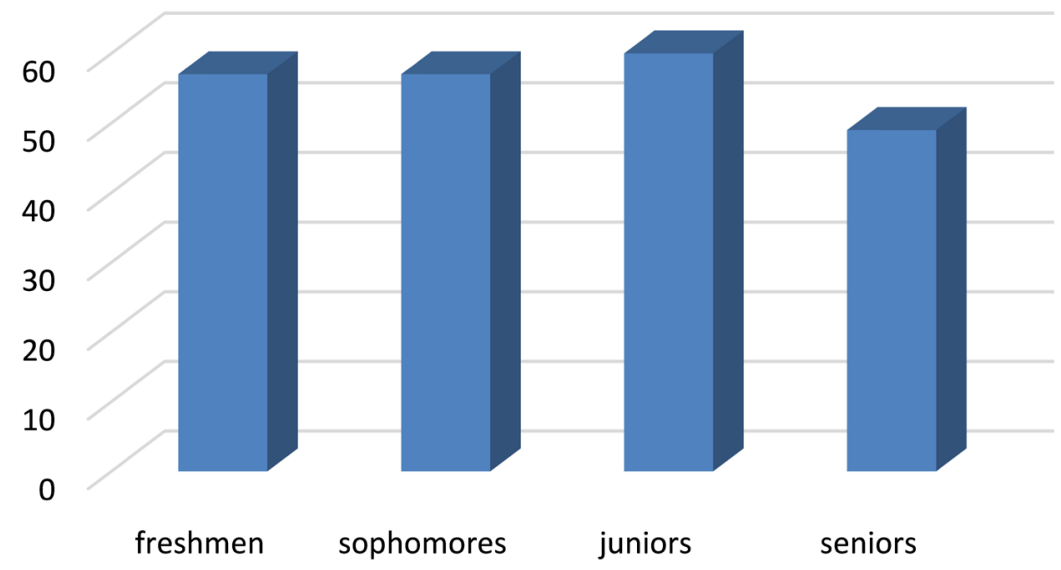

Figure 2. Pre-service teacher grade distribution. 
answers were kept anonymous and they were informed of the purpose of the investigation. The data collection instrument is a 32 -item five-point Likert scale (1 = strongly disagree, 2 = disagree, $3=$ undecided, $4=$ agree, $5=$ strongly agree), where all the seven sub-scale dimensions, namely CK, TK, PK, PCK, TPK, TCK, and TPCK were included. Also, SPSS 19.0 was employed for statistical data analysis.

\subsection{Data Analysis}

The analysis methods adopted in this study were descriptive statistical analysis and inferential statistical analysis. Descriptive statistical analysis mainly dealt with the mean scores and the standard deviation; and inferential statistics was mainly used via Pearson correlational analysis, exploiting independent sample $t$ test and ANOVA to explore the relationships between two background variables (year level and gender) and TPACK as well as the relationships between the two variables (year level and gender) and every level of TPACK. This study used the Technological Pedagogical Content Knowledge scale (TPACK) which was originally developed by Archambault and Crippen (2009) as a date collection instrument. The questionnaire contains 24 items, and adopts five-point Likert scale (1-strongly-disagree, 2-disagree, 3-undecided, 4-agree, and 5-strongly agree), which consist of 7 sub-scales: TK, TCK, TPK, TPCK, PCK, PK, CK. Finally, this research uses SPSS19.0 to carry on the statistics and analysis of the data.

\section{Results and Analysis}

\subsection{Reliability and Validity Analysis}

After the formulation of the first draft of the scale, firstly, the scale has been checked and revised by myself, and educational technologists were invited afterwards to provide advice on the questionnaire for modifying and improving it in order to ensure that the description in the questionnaire can be fully understood by respondents. Finally, the new version of questionnaire was tested on the Internet for further modification and improvement, and SPSS19.0 was applied to test the reliability and validity of the data.

To ensure the reliability of the items in the survey, Cronbach's alpha values (as can be seen in Table 1) were used to indicate internal consistency. The alpha

Table 1. Descriptive statistics of TPACK survey $(\mathrm{N}=223)$.

\begin{tabular}{ccccc}
\hline TPACK scales & No. of items & Mean & Standard deviation & Cronbach's alpha \\
\hline TPK & 4 & 3.3957 & 0.62336 & 0.776 \\
TPCK & 4 & 3.1861 & 0.79844 & 0.773 \\
PCK & 4 & 3.8643 & 0.62180 & 0.775 \\
TK & 3 & 3.1211 & 0.73982 & 0.774 \\
PK & 3 & 3.9851 & 0.58747 & 0.810 \\
CK & 3 & 3.9073 & 0.52216 & 0.793 \\
TCK & 3 & 3.7145 & 0.60255 & 0.799 \\
\hline
\end{tabular}


values for each sub-scale ranging from 0.773 to 0.810 are all within the standard values range from of 0.7 to 0.8 , indicating the high reliability of these items.

General validity tests include two parts, namely content validity and construct validity. A large number of research work on the designs for the questionnaire has been carried out in this study where all the dimensions for measurement of the TPACK scale were included; and therefore it can be stated that the scale constitutes reliable in terms of content validity, namely, the scale can represent what was expected to be measured at a theoretical level. Construct validity shows how much the actual measurement scores can reflect a certain kind of psychological characteristic. The factor analysis approach mainly utilized in this study to analyze all levels of the scale took factor loadings, KMO and Bartlett's test, total values of explained variation and the rotation matrix of all levels as reference standards.

In addition, the factor analysis was performed on a total of 24 enquiries for judging whether the total of 24 items (factors) belongs to the seven latent variables (PK, CK, TK, PCK, TPK, TCK, TPCK) and whether the loading of each item meets the standard. 1) The KMO test result was 0.820 which was above 0.8 showing that the scale had good applicability for factor analysis. In the meantime, Bartlett's test value reached 2602.262 with statistical significance being 0.000 attaining the significance level of 0.05 indicating it being suitable for conducting factor analysis. 2) There were 7 factors with extraction characteristic value greater than 1 together with total values of explained variation of $69.399 \%$. A common factor can be considered reliable if more than $60 \%$, and therefore in this study all the 7 common factors of this scale were retained. 3) Varimax was employed to rotate the initial component matrix, and the internal Kaise normalization method was taken for dealing with the rotation. The initial component matrix converged after 9 iterations, it; and the rotation-completed component matrix has been sorted according to the factor loading values (see Table 2 below for details).

Table 2. By the rotated component matrix.

\begin{tabular}{cccccccc}
\hline & & \multicolumn{5}{c}{ component } \\
\hline & 1 & 2 & 3 & 4 & 5 & 6 & 7 \\
\hline G2 & 0.814 & 0.117 & 0.101 & 0.108 & 0.194 & 0.126 & -0.109 \\
G1 & 0.676 & 0.333 & -0.040 & 0.009 & 0.265 & 0.134 & 0.038 \\
G4 & 0.662 & 0.129 & 0.083 & 0.273 & -0.036 & 0.090 & 0.301 \\
G3 & 0.595 & 0.006 & 0.215 & 0.526 & 0.037 & 0.129 & 0.010 \\
A2 & 0.215 & 0.826 & 0.163 & 0.006 & -0.070 & 0.095 & 0.092 \\
A1 & 0.100 & 0.749 & 0.062 & 0.267 & 0.104 & 0.254 & -0.105 \\
A4 & -0.112 & 0.601 & 0.280 & 0.497 & 0.168 & -0.018 & 0.189 \\
A3 & 0.342 & 0.530 & 0.369 & 0.307 & 0.069 & 0.180 & -0.080 \\
B1 & 0.214 & 0.128 & 0.723 & -0.069 & 0.065 & 0.063 & 0.222 \\
\hline
\end{tabular}




\begin{tabular}{|c|c|c|c|c|c|c|c|}
\hline \multicolumn{8}{|c|}{ Continued } \\
\hline B2 & 0.146 & 0.121 & 0.682 & 0.287 & 0.072 & 0.360 & -0.044 \\
\hline B4 & -0.135 & 0.080 & 0.676 & 0.141 & 0.128 & 0.127 & 0.216 \\
\hline B3 & 0.323 & 0.475 & 0.573 & 0.180 & -0.077 & 0.012 & 0.066 \\
\hline $\mathrm{F} 1$ & 0.148 & 0.245 & 0.177 & 0.785 & 0.007 & 0.014 & -0.023 \\
\hline F3 & 0.227 & 0.410 & -0.220 & 0.612 & 0.079 & 0.055 & 0.380 \\
\hline $\mathrm{F} 2$ & 0.407 & 0.043 & 0.205 & 0.600 & 0.161 & 0.275 & -0.160 \\
\hline $\mathrm{C} 1$ & 0.032 & 0.095 & 0.122 & 0.068 & 0.881 & 0.002 & 0.184 \\
\hline $\mathrm{C} 3$ & 0.168 & 0.071 & -0.029 & 0.032 & 0.867 & 0.112 & 0.105 \\
\hline $\mathrm{C} 2$ & 0.354 & -0.184 & 0.244 & 0.096 & 0.530 & 0.152 & 0.151 \\
\hline D3 & 0.110 & 0.049 & 0.076 & 0.018 & 0.253 & 0.786 & 0.139 \\
\hline D2 & 0.212 & 0.184 & 0.205 & 0.116 & -0.025 & 0.764 & -0.020 \\
\hline D1 & 0.091 & 0.180 & 0.058 & 0.077 & -0.058 & 0.582 & 0.469 \\
\hline $\mathrm{E} 2$ & -0.010 & 0.018 & 0.240 & 0.033 & 0.079 & 0.405 & 0.631 \\
\hline E1 & 0.028 & -0.101 & 0.087 & -0.076 & 0.236 & 0.062 & 0.626 \\
\hline E3 & 0.057 & 0.289 & 0.407 & 0.155 & 0.286 & -0.146 & 0.587 \\
\hline
\end{tabular}

\subsection{Preservice Teachers' TPACK Component Analysis}

Considering the facilitation of the analysis, the mean score of every level of TPACK were compared so as the standard deviation. As shown in Table 1: PK, CK, PCK reached the highest score, while TPCK, TK had the lowest demonstrating that preservice teachers had a good grasp of disciplinary curricula and can effectively apply PK to carry out classroom teaching; while they were slightly less adept in making good use of technology solving practical teaching problems perhaps due to their less exposure to computers and fear of technology. Similarly, scholar Huang's (2013) research on inservice teachers reveals that the ranking of high school teachers' seven sub-dimensions in TPACK from high to low are: PCK $>$ CK $>$ TCK $>$ PK $>$ TPK $>$ TPCK $>$ TK, of which TK is at the lowest level presenting that teachers' technical ability was relatively limited, while PCK ranked the highest level which means that the PTs' level of PCK is quite outstanding. Consistent with the classification of teachers' subject teaching knowledge proposed by Shulman (1987), PCK is the core knowledge across teachers' professional development and is also a watershed for distinguishing novice teachers from expert teachers. Hence, PCK has always been regarded as one of novice teachers' necessary abilities in teacher education.

The lack of TPK among pre-service teachers is significantly closely correlated to the training mode and curriculum for pre-service teachers. Normally, preservice teachers' training in our country adopts the mode of "the specialty, the skill and the internship" making it possible for students failing to combine the three elements of the specialty, the technique, and the teaching skill together. As a result, preservice teachers behave badly on TPK level. Additionally, pre-service 
teachers usually deploy a less complicated teaching method during the internship leading to their students failing to accomplish the transfer of complex knowledge. Furthermore, their daily skills training shows deficiency in targeted guidance so that preservice teachers cannot optimize information technology and professional knowledge to solving practical teaching problems.

\subsection{Correlation of All Levels of Preservice Teachers' TPACK Analysis}

For the purpose of exploring the correlation between the every level of TPACK, their correlations were illustrated in Table 3 below: 1) A statistically significantly positive correlation was found between TPK and the other 6 elements $(P=0.000$ $<0.01$ ), of which TPK level and TK level were the most closely related indicating that the pre-service teachers' TK were moderately positively related to the usage of TPK. Consistent with the previous studies (Zhao, Li, \& Xie, 2018), from a certain perspective, the preservice teachers' TK knowledge or ability had a strong correlation with the colleges' training program for preservice teachers. 2) A statistically significantly positive correlation was discovered between TPCK and the other 6 elements $(P=0.000<0.01)$, among which TPCK was strongest related to TK demonstrating that the level of pre-service teachers' TK directly affected their TPACK. The level of preservice teachers' command of information technology can be influential on whether they would integrate information technology with classroom teaching. 3) A statistically significantly positive correlation was detected between PCK and the other 6 elements $(P=0.000<0.01)$, among which the correlation between PCK and CK constituted the highest one illustrating that pre-service teachers' PCK is directly connected with their CK. This finding echoes the research result of Cox and Graham (2009) that PCK is intimately linked to the specific subjects, topics and original knowledge systems that students learn. 4) A statistically significantly positive correlation was penetrating between TCK and the other 6 elements $(P=0.000<0.01)$, among which TCK and CK had the tightest correlation representing that the TCK possessed by preservice teachers and their $\mathrm{CK}$ are moderately related. The level of pre-service teachers' command of CK of different disciplines determined how much information technology would be used in a particular discipline.

Further, the influence of gender, year level and other personal background factors on all levels of TPACK has been investigated. The independent sample t-test has been performed to measure the differences between the two genders at all levels of TPACK. Regarding the statistical number of the two genders, the number of female participants was slightly more than that of males, consistent with the situation that generally more females than males study in normal schools. However, notably, the ratio of male candidates to females in the present study was close to one to one, which enable to thoroughly elaborate the differences between the two genders at all levels of TPACK, and the statistical requirements were theoretically satisfied. As shown in Table 4, the significance of TPK, TPCK, PCK, TK, PK, and TCK all attained over 0.05 , illustrating that TPK, 
Table 3. Correlation between TPACK.

\begin{tabular}{cccccccc}
\hline & TPK & TPCK & PCK & TK & PK & CK & TCK \\
\hline TPK & 1 & & & & & & \\
TPCK & $0.561^{* *}$ & 1 & & & & & \\
PCK & $0.430^{* *}$ & $0.451^{* *}$ & 1 & & & & \\
TK & $0.613^{* *}$ & $0.626^{* *}$ & $0.433^{* *}$ & 1 & & & \\
PK & $0.517^{* *}$ & $0.531^{* *}$ & $0.569^{* *}$ & $0.461^{* *}$ & 1 & & \\
CK & $0.482^{* *}$ & $0.499^{* *}$ & $0.578^{* *}$ & $0.448^{* *}$ & $0.455^{* *}$ & 1 & \\
TCK & $0.431^{* *}$ & $0.495^{* *}$ & $0.478^{* *}$ & $0.447^{* *}$ & $0.438^{* *}$ & $0.524^{* *}$ & 1 \\
\hline
\end{tabular}

${ }^{* *}$ Correlation is significant at the 0.01 level (2-tailed).

Table 4. Gender differences in TPACK.

\begin{tabular}{cccccc}
\hline TPACK scales & Gender & number & $\mathrm{M}$ & $\mathrm{SD}$ & t-value \\
\hline \multirow{2}{*}{ TPK } & female & 126 & 3.3810 & 0.58199 & -0.395 (n.s.) \\
& male & 97 & 3.4149 & 0.67593 & \\
TPCK & female & 126 & 3.2341 & 0.71606 & 0.995 (n.s.) \\
& male & 97 & 3.1237 & 0.89423 & \\
PCK & female & 126 & 3.8591 & 0.68301 & -0.143 (n.s.) \\
& male & 97 & 3.8711 & 0.53536 & \\
TK & female & 126 & 3.1905 & 0.70984 & \multirow{2}{*}{1.602 (n.s.) } \\
& male & 97 & 3.0309 & 0.77143 & \\
PK & female & 126 & 3.9683 & 0.51713 & -0.470 (n.s.) \\
& male & 97 & 4.0069 & 0.67009 & \\
CK & female & 126 & 3.9709 & 0.50247 & $2.088^{*}$ \\
& male & 97 & 3.8247 & 0.53811 & \\
TCK & female & 126 & 3.6667 & 0.58878 & -1.354 (n.s.) \\
& male & 97 & 3.7766 & 0.61750 & \\
\hline
\end{tabular}

${ }^{*} p<0.05$.

TPCK, PCK, TK, PK, and TCK were not statistically different on the level of gender. CK level, however, had statistical differences between the two genders ( $\mathrm{t}$ $=2.088, p<0.05)$. Females' level of content knowledge was higher than that of males. The reason for the difference is largely related to the differences between the way of thinking the habit of study and personality of the two genders. More specifically, females took the professional curriculums more seriously and therefore had a better grasp of the knowledge. According to previous studies, females account for the majority of top-ranked students in the class, implying that females have a better grasp of CK.

In this research one-way ANOVA was carried out to measure the differences in variable of year level on all sub-scales of TPACK, so as to more accurately 
Table 5. Differences in TPACK across year levels.

\begin{tabular}{|c|c|c|c|c|c|c|c|}
\hline Year level & $\begin{array}{l}\text { TPK } \\
\text { (mean, } \\
\text { S.D.) }\end{array}$ & $\begin{array}{l}\text { TPCK } \\
\text { (mean, } \\
\text { S.D.) }\end{array}$ & $\begin{array}{l}\text { PCK } \\
\text { (mean, } \\
\text { S.D.) }\end{array}$ & $\begin{array}{c}\text { TK } \\
\text { (mean, } \\
\text { S.D.) }\end{array}$ & $\begin{array}{c}\text { PK } \\
\text { (mean, } \\
\text { S.D.) }\end{array}$ & $\begin{array}{c}\text { CK } \\
\text { (mean, } \\
\text { S.D.) }\end{array}$ & $\begin{array}{c}\text { TCK } \\
\text { (mean, } \\
\text { S.D.) }\end{array}$ \\
\hline 1) Freshman & $3.4(0.7)$ & $2.9(0.9)$ & $3.9(0.5)$ & $3.2(0.6)$ & $3.9(0.8)$ & $3.9(0.6)$ & $3.8(0.6)$ \\
\hline 2) Sophomore & $3.3(0.7)$ & $2.9(1.0)$ & $3.6(0.9)$ & $3.1(0.7)$ & $4.1(0.5)$ & $3.9(0.5)$ & $3.7(0.7)$ \\
\hline 3) Junior & $3.4(0.5)$ & $3.5(0.7)$ & $4.1(0.4)$ & $3.0(0.8)$ & $4.0(0.6)$ & $4.0(0.4)$ & $3.8(0.4)$ \\
\hline 4) Senior & $3.3(0.7)$ & $3.2(0.8)$ & $3.9(0.5)$ & $3.4(0.8)$ & $4.0(0.6)$ & $3.8(0.7)$ & $3.5(0.6)$ \\
\hline$F($ ANOVA) & 1.075 & 3.105 & 4.182 & 0.277 & 0.052 & 0.284 & 0.174 \\
\hline Tukey test & & $(3)>(1)$ & $(2)>(1)$ & & & & \\
\hline
\end{tabular}

describe the pre-service teachers' characteristics of TPACK. It can be demonstrated from Table 5 that there is no difference regarding the variable of year level on the level of TPK, TK, PK, CK, and TCK. TPK (F = 1.075, $P=0.360)$; TK $(\mathrm{F}=1.296, P=0.277) ; \mathrm{PK}(\mathrm{F}=2.616, P=0.052)$, CK $(\mathrm{F}=1.075, P=0.284)$, TCK $(\mathrm{F}=1.673, P=0.174)$. While significant differences existed between TPCK and PCK concerning the variable of year level: TPCK (F = 3.105, $P=0.027)$; PCK (F $=4.182, P=0.360)$. Via the Tukey post-hoc test, it can be stated that there was a significant difference in TPCK between the third year and the first year preservice teachers, $(P=0.034)$ and also the third years' TPCK level was higher than the first years', which is in line with the conclusion of Dong et al. (2014) study which shows that the TPACK of third-year students is higher than that of freshmen. Via the Tukey post-hoc test in the same vein, the sophomore's PCK level is significantly different with the freshman's $(P=0.008)$ and the PCK of the sophomore was higher than that of the freshman, revealing that the PCK of PTs had the correlation with the variable of year level and higher year levels behaved better than lower year levels (Dong, Sang, \& Cai, 2014). This can also clarifies the significance of PCK and TPACK in teacher education, which has a significantly positive effect on the development of teacher education in China.

\section{Conclusion and Recommendations}

\subsection{Conclusion}

First of all, all levels of pre-service teachers' TPACK competency were at an intermediate level, among which TPK and TPCK were at a relatively lower level, and the TK level was the lowest, displaying that pre-service teachers' skills concerning technology need further improvement.

What's more, the significant correlation existed between every two levels of TPACK for pre-service teachers, which echoes the conclusions of Schmidt's study (Schmidt et al., 2009) and Archambault's, that is, TPK, TPCK, PCK, TK, PK, TCK, CK are significantly related. In terms of the technological level, TPK and TPCK had a relatively greater impact on TK, while with regard to the content level, PCK and TCK are more influential on CK. 
Thirdly, differences in TPACK competency among individuals under different personal backgrounds occurred, specifically, male and female pre-service teachers had significant differences in CK knowledge, that is, female teachers had better control of subject teaching knowledge than males. Additionally, there was no significant difference between male and female pre-service teachers in TPK, TPCK, PCK, TK, PK, and TCK. Pre-service teachers of different year levels also showed differences in TPACK competency.

\subsection{Suggestions}

TPACK structure conforms to the development of the times making it clear that modern teachers ought to not only have technological knowledge, but also enable to apply the information technology to teaching for solving practical problems. TPACK represents a kind of complex and comprehensive ability; based on the relevant research in recent years, researchers have paid more and more attention to the study research on pre-service teachers' integration of technology with teaching, which means that new teachers should not only pay attention to the usage of information technology in the teaching, but to the integration of information technology and teaching as well so that teaching methods can be transformed and improved, and the integration of information technology and curriculum can be completely accomplished. In other words, how to effectively integrate information technology with teaching has become a vital issue in this field. To this end, the present study would put forward requirements for the training of pre-service teachers for the future study.

First, the construction of the learning environment for preservice teachers needs improvement. As the cradle of cultivating preservice teachers, normal colleges should be required to update information-based teaching equipment timely, increase investment in teaching resources to realize the sharing of digital teaching resources, build more relevant digital laboratories in order to meet pre-service teachers' needs in software and hardware for continuous study.

Furthermore, the PCK possessed by preservice teachers in different disciplines alters, as well as the information technology tools used in different disciplines. For instance, preservice teachers of mathematics will apply geometric sketchpads for teaching. Therefore, in modern educational technology compulsory curriculums for preservice teachers, ICT teachers need to develop specific teaching designs aimed at students' different disciplinary settings, and integrate information technology methods of specific disciplines into the curriculum for the purpose of preservice teachers absorbing the essence of the information integrated teaching from these specific disciplines. Additionally, the TPACK competency training for preservice teachers also needs to rely on specialized courses teachers in order to enable students to subtly perceive all levels of TPACK in their daily learning; and meanwhile the training also needs to focus on training preservice teachers' all levels of knowledge.

Last but not least, the increase of educational practical activities is indicated. 
To be more specific, educational practice needs to be arranged appropriately, and information-based teaching environments such as micro-peer teaching need to be made full use of for the purpose of providing preservice teachers with real teaching scenes, so that students can do stocktaking during the practice and make progress in TPACK competency. In carrying out group cooperation learning, the attention needs to be paid to the differences between males and females with respect to their utilizations of IT, and in the meantime proper grouping considering the number of males and females in every single team is a must for this helping students obtain technical knowledge efficiently in group cooperation learning. The promotion of pre-service teacher TPACK is of great significance to the development of normal education.

\section{Funding}

Supported by Nanjing Normal University Teaching Reform Project (Project No.: 1612206000-1JG16).

\section{Conflicts of Interest}

The authors declare no conflicts of interest regarding the publication of this paper.

\section{References}

Angeli, C., \& Valanides, N. (2009). Epistemological and Methodological Issues for the Conceptualization, Development, and Assessment of ICT-TPCK: Advances in Technological Pedagogical Content Knowledge. Computers \& Education, 52, 154-168. https://doi.org/10.1016/j.compedu.2008.07.006

Archambault, L., \& Crippen, K. (2009). Examining TPACK among K-12 Online Distance Educators in the United States. Contemporary Issues in Technology and Teacher Education, 9, 1-88.

Cox, S., \& Graham, C. R. (2009). Diagramming TPACK in Practice: Using and Elaborated Model of the TPACK Framework to Analyze and Depict Teacher Knowledge. TechTrends, 53, Article No. 60. https://doi.org/10.1007/s11528-009-0327-1

Cuban, L., Kirkpatrick, H., \& Peck, C. (2001). High Access and Low Use of Technologies in High School Classrooms: Explaining an Apparent Paradox. American Educational Research Journal, 38, 813-834. https://doi.org/10.3102/00028312038004813

Dai, J., Ren, Y., \& Li, W. (2018). Investigation and Analysis of the Status Quo of Pre-Service Biology Teachers' TPACK-Instance East China Normal University (ECNU) and National Changhua University of Education (NCUE). Biology Teaching, 43, 14-17.

Dong, Y., Sang, G., \& Cai, J. (2014). An Empirical Study on Pre-Service Teachers' TPACK. Teacher Education Research, 26, 36-43.

Huang, D., Gao, L., \& Wang, H. (2013). Investigation and Analysis of TPACK Status Quo of High School Teachers-A Report from City of Initial N. Modern Educational Technology, No. 2, 37-51.

Mishra Koehler, M. (2009). TPCK-Technological Pedagogical Content Knowledge. http://www.tpck.org

Mishra, P., \& Koehler, M. J. (2006). Technological Pedagogical Content Knowledge: A 
Frame work for Teacher Knowledge. Teachers College Record, 108, 1017-1054. https://doi.org/10.1111/j.1467-9620.2006.00684.x

Schmidt, D. A., Baran, E., Thompson, A. D. et al. (2009). Technological Pedagogical Content Knowledge (TPACK): The Development and Validation of an Assessment Instrument for Pre-Service Teachers. Journal of Research on Technology in Education, 42, 123-149. https://doi.org/10.1080/15391523.2009.10782544

Shulman, L. (1987). Knowledge and Teaching: Foundations of the New Reform. Harvard Educational Review, 57, 1-23. https://doi.org/10.17763/haer.57.1.j463w79r56455411

Shulman, L. S. (1986). Those Who Understand: Knowledge Growth in Teaching. Educational Researcher, 15, 4-14. https://doi.org/10.3102/0013189X015002004

Xu, Z. (2012). Subject Teaching Knowledge Supported by Information Technology: Origin, Evolution, Structural Model and Educational Implications. Research in Educational Development, No. 10, 62-68.

Yuan, X. (2014). Research on the Integration of Information Technology and Junior Middle School Physics Curriculum under the Background of New Curriculum Reform. Mathematical and Chemical Learning, 3, 53-57.

Zhan, Y., \& Ren, Y. (2010). A Brief Introduction to the Connotation and Research Status of TPACK. Distance Education Journal, 28, 78-87.

Zhang, T., \& Wang, L. (2016). Investigation and Research on Pre-service Teachers' TPACK-Instance Pre-Service Mathematics Teachers. Journal of Southwest China Normal University (Natural Science Edition), 41, 221-225.

Zhao, L., Li, Y., \& Xie, J. (2018). TPACK of Pre-Service Information Technology Teachers from Local Universities: Influencing Factors and Construction Strategies. Modern Distance Education, No. 3, 29-36. 